\title{
Racial Differences in Seasonal Variation in Election and Non-election Years in the Male to Female Ratio at Birth in the United States \\ V Grech, T Borg
}

\begin{abstract}
S
Objective: In humans, male births exceed female births. This ratio is conventionally expressed to $\mathrm{M} / \mathrm{F}$ and is influenced by a large number of factors, including stress. This study was carried out in order to ascertain whether the known seasonal variation in $\mathrm{M} / \mathrm{F}$ in the United States (peaking in June) is affected by the quadrennial elections (November), and whether any such influences vary by race.
\end{abstract}

Methods: Births by gender and by race for 2003-13 were obtained from the website of the Centers for Disease Control and Prevention for the four available races: White, Black/African American, Asian/Pacific Islander and American Indian/Alaska Native. Election years were 2004, 2008 and 2012. Seasonality tests were carried for the entire group and for White and Black/African American births.

Results: This study analysed 45138496 live births (23102106 males, 22036390 females, M/F 0.51180). Overall, $\mathrm{M} / \mathrm{F}$ was lowest in the election years rising, then falling again to the next election year $(\mathrm{p}=\mathrm{ns})$. This pattern was present for White and Asian/Pacific Islander births but not for Black/African American or American Indian/Alaskan Native births. Overall and for White births, only election year plus 3 (year just before election) showed seasonal variation $(\mathrm{p}<0.01)$.

Conclusion: Seasonality may have been disturbed/reduced in most years due to elections. Black births may have been unaffected due to chronic stress caused by socio-economic dampening of $\mathrm{M} / \mathrm{F}$ trends.

Keywords: Birth Rate/trends, infant, newborn, periodicity, seasons, sex ratio, United States From: Department of Paediatrics, Mater Dei Hospital, Malta and National Statistics Office, Valletta, Malta.

Correspondence: Professor V Grech, Department of Paediatrics, Mater Dei Hospital, Malta E-mail: victor.e.grech@gov.mt 


\section{INTRODUCTION}

In humans, male births exceed female births and this ratio is conventionally referred to $\mathrm{M} / \mathrm{F}$, denoting male births divided by total births. M/F may be influenced by a large number of factors (1) and has been shown to exhibit seasonal variation in various parts of the world (2). Early studies had shown a low M/F in February and March and a high $\mathrm{M} / \mathrm{F}$ in summer in various parts of the world (3) with similar patterns in the United States more recently (4).

The Trivers-Willard hypothesis proposes that individuals who are able to influence their offspring gender ratio in accordance with their environment are likelier to procreate, thereby dispersing these advantageous genes. In polygynous species, only the fittest males reproduce. For this reason, parental investment in a "good quality" son may yield greater numbers of descendants than an equivalent investment in a "good quality" daughter. It is thus be advantageous for a mother to produce sons when she has good resources, and daughters when she does not. This is known as the Trivers-Willard hypothesis (5). For the same reasons, it has been postulated that the findings that stress reduces $\mathrm{M} / \mathrm{F}$ may be explained by the TriversWillard hypothesis.

The abovementioned seasonal patterns of live births support the Trivers-Willard hypothesis since the birth of offspring in favourable seasonal conditions increases the chances of said offsprings' survival. It has also been recently shown that in the US, for over 2003-13, $\mathrm{M} / \mathrm{F}$ was highest in Asian/Pacific Islanders, followed by White, American Indian/Alaska Native and Black/African American births, with these differences occurring as statistically significant levels (4). Significant seasonality was present overall in the US, with a peak in June, for Whites more than Black/African American, and absent in the rest. It was conjectured that the traditionally lower M/F found in Black/African and American Indian/Alaskan births may be stress-related in that these races are overall socio-economically underprivileged and hence 
chronically stressed (6). It was therefore also hypothesised that the dampened seasonality noted in Black/African American births might also be due to this phenomenon (4).

In the US, Election Day is set by law for the general election of public officials. The event and the associated political campaigns have been shown to engender significant stress in the populace $(7,8)$. Election day always occurs on the Tuesday after the first Monday in November (November $2^{\text {nd }}$ to the $8^{\text {th }}$ ) and Presidential Elections occur every four years. This provides a unique opportunity to ascertain whether election campaigns and the elections themselves exert any influence on $\mathrm{M} / \mathrm{F}(9)$.

This study was carried out in order to ascertain whether the seasonal variation in $\mathrm{M} / \mathrm{F}$ in the United States is influenced by the Presidential Elections and whether there are any racial variations.

\section{METHODS}

\section{Data and definitions}

Births by gender and by race for 2003-13 were obtained from the website of the Centers for Disease Control and Prevention, in the CDC Wonder section (http://wonder.cdc.gov/natality.html). The data was available for four races: White, Black/African American, Asian/Pacific Islander and American Indian/Alaska Native. Ethical approval was irrelevant as this analysis comprised a large and completely anonymous dataset. For the same reason, informed consent was unnecessary.

Election years were 2004, 2008 and 2012. Election years plus one were 2005, 2009 and 2013. Election years plus two were 2006 and 2010. Election years plus three (pre-election years) were 2003, 2007 and 2011. Seasonality tests were carried out on the abovementioned year groups for all Americans, White Americans and Black/African Americans. American 
Indian/Alaskan Native and Asian or Pacific Islander were not analysed for seasonality due to the (relatively) small numbers of these births.

\section{Statistical analysis}

Prior to any use of statistical tools, a series of tests were done on the data to check for homogeneity of variance, independence of observations and normality. Data was also plotted to check for obvious outliers.

Seasonality was analysed using Demetra (version 1.0.4.323) and a model based method (X12) was operated to fit an Autoregressive Integrated Moving Average (ARIMA) model to the data. A series of seasonality tests were carried out on each time series after the ARIMA model was determined. These included non-parametric tests for stable seasonality using Friedman and Kruskall-Wallis tests, a test for the presence of seasonality assuming stability, evolutive seasonality test and combined seasonality test. The combined seasonality test passes if the first three tests pass at the $1 \%(\mathrm{p}<0.01)$ level and if the evolutive seasonality test fails at the $20 \%(p>0.2)$ level.

Further tests on seasonality using Analysis of variance (ANOVA) were carried with the null hypothesis showing no statistically significant difference between the means of each month. ANOVA was carried out with SPSS (Statistical Package for the Social Sciences, International Business Machines Corporation, New York, USA). A p value $<0.05$ was taken to represent a statistically significant result.

The quadratic equations of Fleiss were used to calculate exact 95\% confidence limits.(10) Chi tests and chi tests for trend were used for trend testing of male and female births using the Bio-Med-Stat Excel add-in for contingency tables (Peter Slezak, Bratislava, Slovakia).(11). 


\section{RESULTS}

This study analysed a total of 45138496 live births as 23102106 males and 22036390 females (M/F 0.51180, 95\% CI 0.51166-0.51195) born over the period 2003-13. Annual totals by race for election years $(2004,2008,2012$, election years plus one $(2005,2009,2013)$, election years plus two $(2006,2010)$ and election years plus three (pre-election years: 2003, 2007, 2011) are shown in table 1.

Overall, $\mathrm{M} / \mathrm{F}$ was lowest in the election years rising, then falling again to the election year. This pattern was present for White and Asian/Pacific Islander births but not for Black/African American or American Indian/Alaskan Native births. These trends where not statistically significant, even when data was pooled for White and Asian/Pacific Islander births. Monthly M/F for the entire period is shown in figure 1 . The same data for election years (2004, 2008 and 2012), election years plus one (2005, 2009 and 2013), election years plus two (2006 and 2010) and election years plus three (pre-election years: 2003, 2007 and 2011) are shown in figures 2 to 5 respectively.

ARIMA $(0,1,1)(0,1,1)$ was fitted on all data and for three of the four time series being analysed. For the total American population, i.e. including all four races, of all four time series, election year plus three exhibited a seasonal variation at $\mathrm{p}<0.01$. Combined seasonality was absent in election years and election years plus one (Table 2). Nevertheless, ANOVA results show significant differences between months at $\mathrm{p}<0.05$ for all years under study.

For election years plus two (2006 and 2010), the time series was too short for ARIMA modelling. Additionally, the data violated the assumptions for ANOVA testing. The KruskallWallis test was used instead to check for seasonality for summated quarterly rather than monthly data. Seasonality was not present at even for quarterly data.

White American births exhibited the same seasonal pattern as total Americans, with seasonal variation present in the election years plus three (time series at $\mathrm{p}<0.01$ ). Similarly, 
ANOVA results for White American births confirmed the seasonality pattern for the time series grouping mentioned earlier. Seasonality was absent in Black/African American births for all time series combinations under study. For the other two races (Asian/Pacific Islander and American Indian/Alaska Native), the dataset was too small to attempt to perform seasonality analysis.

\section{DISCUSSION}

\section{Overall}

A previous study has shown significant seasonality in the US overall, with an M/F peak in June (4). For the total population (all four races), ANOVA showed significant differences between months at $\mathrm{p}<0.05$ for all years under study.

However, analysis by amalgamated years showed that only election year plus three exhibited significant seasonal variation. It may be hypothesised that seasonality was absent and therefore possibly disturbed or reduced by stress engendered by electoral campaigns in election years and election years plus one. However, it is difficult to extend this explanation to election years plus two. A possible explanation for this is a type 2 error since there was less data (one less year) in this group.

This socio-economic dampening effect on $\mathrm{M} / \mathrm{F}$ is supported by the observed rise in $\mathrm{M} / \mathrm{F}$ in what may be a recovery from stress after election years and a decline back down as the elections approach, since this is only observed in the more socio-economically privileged groups, White and Asian/Pacific Islander, but not for Black/African American or American Indian/Alaskan Native births. 


\section{Racial differences}

A previous study had also shown significant seasonality in $M / F$ for Whites more than Black/African American, and absent seasonality in the rest.(4) It had also been shown that M/F was significantly highest in Asian/Pacific Islander $(\mathrm{p}<<0.0001)$, followed by White $(\mathrm{p}=0.002)$, American Indian/Alaska Native ( $\mathrm{p}=0.04)$ and Black/African American births.(4)

In this study White American births exhibited the same seasonal pattern as the abovementioned totals. This was the largest population and hence the group least likely to result in a type 2 error.

Seasonality was absent in Black/African American births for all time series combinations. This may be due to the fact that Black births were far less than White births and therefore the possibility of a type 2 error cannot be discounted. However, it is possible that seasonality is truly absent in Black births since both ANOVA and combined seasonality testing indicate absence of seasonality. This may be because as already alluded to, this population is chronically stressed due to socio-economic circumstances. Seasonality may therefore be dampened, and M/F effects due to election campaigns/elections may therefore not be manifest.

\section{AUTHORS' NOTE}

There is nothing to disclose. There was no financial assistance whatsoever for the production of this paper. There are no potential conflicts of interest, financial or otherwise. 


\section{REFERENCES}

1. James WH. The human sex ratio. Part 1: A review of the literature. Hum Biol. 1987; 59: 721-52.

2. Melnikov V. Seasonal inconstancy of human sex ratio at birth. Early Hum Dev. 2015; 91: 817-21.

3. Huntington E. 1938. Season of Birth. New York: John Wiley and Sons, 1938.

4. Grech V, Borg T. Seasonal variation by race in the male to female ratio at birth in the United States. West Indian Med J. - in press.

5. Trivers RL, Willard DE. Natural selection of parental ability to vary the sex ratio of offspring. Science. 1973; 179: 90-2.

6. Grech V. State and regional differences in the male-to-female ratio at birth in the United States, 1995-2012. West Indian Med J. - in press.

7. Stanton SJ, Beehner JC, Saini EK, Kuhn CM, Labar KS. Dominance, politics, and physiology: voters' testosterone changes on the night of the 2008 United States presidential election. PLoS One. 2009; 4:e7543.

8. Stanton SJ, Labar KS, Saini EK, Kuhn CM, Beehner JC. Stressful politics: voters' cortisol responses to the outcome of the 2008 United States Presidential election. Psychoneuroendocrinology. 2010; 35: 768-74.

9. Timpone RJ. Structure, behavior, and voter turnout in the United States. Am Polit Sci Rev 1998; 92: 145-158.

10. Fleiss JL. Statistical methods for rates and proportions. New York: John Wiley and Sons, 1981:14-15 (2nd edition).

11. Slezák P. Microsoft Excel add-in for the statistical analysis of contingency tables. Int J Innovation Educ Res 2014; 2: 90-100. 
Table 1: Annual totals by race and male: female birth ratios for amalgamated years (election, election $+1,+2$ and +3 )

\begin{tabular}{|c|c|c|c|c|c|}
\hline & Election Year & Election Year+1 & Election Year+2 & Election Year+3 & Total \\
\hline \multicolumn{6}{|c|}{ American Indian/Alaskan Native } \\
\hline Male & 70992 & 71034 & 47981 & 70925 & 260932 \\
\hline Female & 68565 & 68435 & 46500 & 67989 & 251489 \\
\hline Total & 139557 & 139469 & 94481 & 138914 & 512421 \\
\hline UCL & 0.51132 & 0.51194 & 0.51103 & 0.51320 & 0.51058 \\
\hline$M / F$ & 0.50870 & 0.50932 & 0.50784 & 0.51057 & 0.50921 \\
\hline $\mathbf{L C L}$ & 0.50607 & 0.50669 & 0.50464 & 0.50794 & 0.50784 \\
\hline \multicolumn{6}{|c|}{ Asian or Pacific Islander } \\
\hline Male & 388955 & 385772 & 252057 & 376193 & 1402977 \\
\hline Female & 366155 & 362098 & 235874 & 353413 & 1317540 \\
\hline Total & 755110 & 747870 & 487931 & 729606 & 2720517 \\
\hline UCL & 0.51622 & 0.51696 & 0.51799 & 0.51676 & 0.51630 \\
\hline$M / F$ & 0.51510 & 0.51583 & 0.51658 & 0.51561 & 0.51570 \\
\hline LCL & 0.51397 & 0.51469 & 0.51518 & 0.51446 & 0.51511 \\
\hline \multicolumn{6}{|c|}{ Black or African American } \\
\hline Male & 976945 & 977766 & 663794 & 970152 & 3588657 \\
\hline Female & 944064 & 947746 & 639112 & 938272 & 3469194 \\
\hline Total & 1921009 & 1925512 & 1302906 & 1908424 & 7057851 \\
\hline UCL & 0.50927 & 0.50850 & 0.51033 & 0.50906 & 0.50883 \\
\hline$M / F$ & 0.50856 & 0.50780 & 0.50947 & 0.50835 & 0.50846 \\
\hline LCL & 0.50785 & 0.50709 & 0.50861 & 0.50764 & 0.50809 \\
\hline \multicolumn{6}{|c|}{ White } \\
\hline Male & 4862592 & 4811220 & 3267340 & 4908388 & 17849540 \\
\hline Female & 4634319 & 4577124 & 3112283 & 4674441 & 16998167 \\
\hline Total & 9496911 & 9388344 & 6379623 & 9582829 & 34847707 \\
\hline UCL & 0.51234 & 0.51279 & 0.51254 & 0.51252 & 0.51238 \\
\hline$M / F$ & 0.51202 & 0.51247 & 0.51215 & 0.51221 & 0.51222 \\
\hline $\mathrm{LCL}$ & 0.51170 & 0.51215 & 0.51176 & 0.51189 & 0.51205 \\
\hline \multicolumn{6}{|c|}{ All } \\
\hline Male & 6299484 & 6245792 & 4231172 & 6325658 & 23102106 \\
\hline Female & 6013103 & 5955403 & 4033769 & 6034115 & 22036390 \\
\hline Total & 12312587 & 12201195 & 8264941 & 12359773 & 45138496 \\
\hline UCL & 0.51191 & 0.51218 & 0.51228 & 0.51207 & 0.51195 \\
\hline$M / F$ & 0.51163 & 0.51190 & 0.51194 & 0.51179 & 0.51180 \\
\hline $\mathrm{LCL}$ & 0.51135 & 0.51162 & 0.51160 & 0.51152 & 0.51166 \\
\hline
\end{tabular}

UCl: Upper confidence interval. LCl: Lower confidence interval.

Election years: 2004, 2008, 2012

Election years plus one: 2005, 2009, 2013.

Election years plus two: 2006, 2010.

Election years plus three (pre-election years): 2003, 2007, 2011. 
Table 2: ANOVA and five seasonality test results on all four American races, and on separately on White and Black/African births

\begin{tabular}{|c|c|c|c|c|}
\hline & ANOVA and five seasonality tests & All races & Whites & $\begin{array}{l}\text { Black / } \\
\text { African }\end{array}$ \\
\hline \multirow{7}{*}{ All Years } & ANOVA & $<0.0001$ & $<0.0001$ & 0.005 \\
\hline & Friedman test & $<0.0001$ & $<0.0001$ & 0.0005 \\
\hline & Kruskall-Wallis test & $<0.0001$ & $<0.0001$ & 0.0006 \\
\hline & Test for presence of seasonality assuming stability & $<0.0001$ & $<0.0001$ & 0.0009 \\
\hline & Evolutive seasonality test & 0.7993 & 0.4233 & 0.4649 \\
\hline & Combined seasonality test & SP & SP & SP \\
\hline & ANOVA & 0.001 & 0.006 & 0.533 \\
\hline \multirow{5}{*}{$\begin{array}{l}\text { Election } \\
\text { Years (2004, } \\
2008 \text { and } \\
2012)\end{array}$} & Friedman test & 0.006 & 0.0191 & 0.3142 \\
\hline & Kruskall-Wallis test & 0.0195 & 0.0316 & 0.3944 \\
\hline & Test for presence of seasonality assuming stability & 0.001 & 0.0073 & 0.4215 \\
\hline & Evolutive seasonality test & 0.9973 & 0.7674 & 0.1174 \\
\hline & Combined seasonality test & SA & SA & SA \\
\hline \multirow{6}{*}{$\begin{array}{l}\text { Election } \\
\text { Years plus } \\
\text { one (2005, } \\
2009 \text { and } \\
2013)\end{array}$} & ANOVA & 0.01 & 0.008 & 0.109 \\
\hline & Friedman test & 0.0069 & 0.0027 & 0.1986 \\
\hline & Kruskall-Wallis test & 0.0243 & 0.0322 & 0.1233 \\
\hline & Test for presence of seasonality assuming stability & 0.0032 & 0.0032 & 0.103 \\
\hline & Evolutive seasonality test & 0.4851 & 0.5399 & 0.254 \\
\hline & Combined seasonality test & SA & SA & SA \\
\hline \multirow{6}{*}{$\begin{array}{c}\text { Election } \\
\text { Years plus } \\
\text { three (2003, } \\
2007 \text { and } \\
2011)\end{array}$} & ANOVA & 0.0001 & 0.001 & 0.211 \\
\hline & Friedman test & 0.0013 & 0.0002 & 0.1216 \\
\hline & Kruskall-Wallis test & 0.0081 & 0.0063 & 0.1576 \\
\hline & Test for presence of seasonality assuming stability & 0.0001 & 0.0001 & 0.1209 \\
\hline & Evolutive seasonality test & 0.8634 & 0.7954 & 0.4627 \\
\hline & Combined seasonality test & SP & SP & SA \\
\hline
\end{tabular}

$\mathrm{SA}=$ seasonality absent, $\mathrm{SP}=$ seasonality present.

The Kruskall-Wallis test was used for election years plus two (2006 and 2010). 


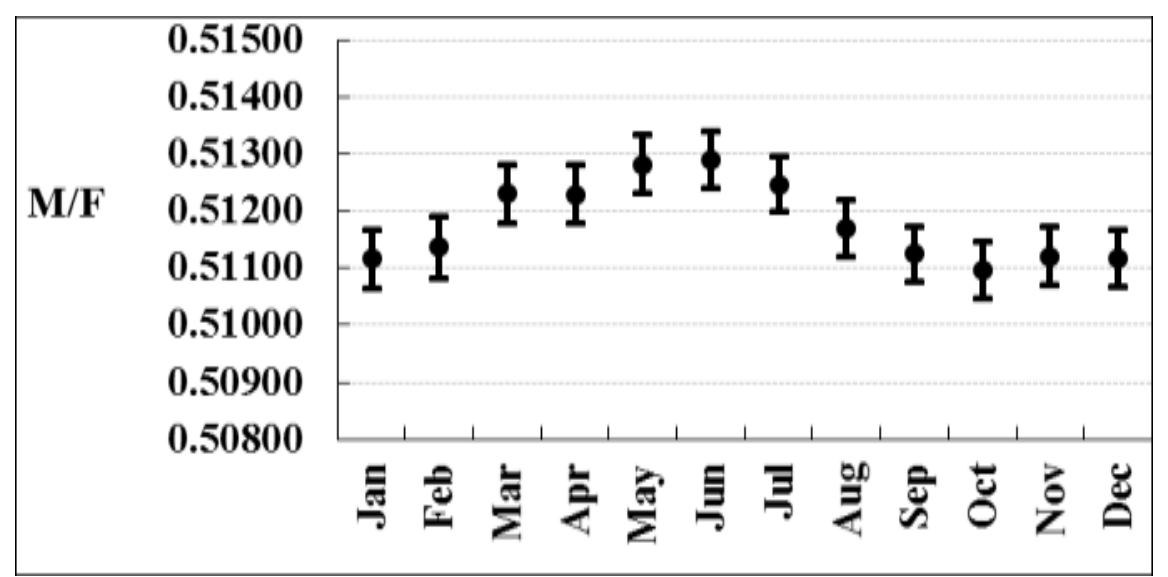

Fig 1: Monthly M/F for 2003-13.

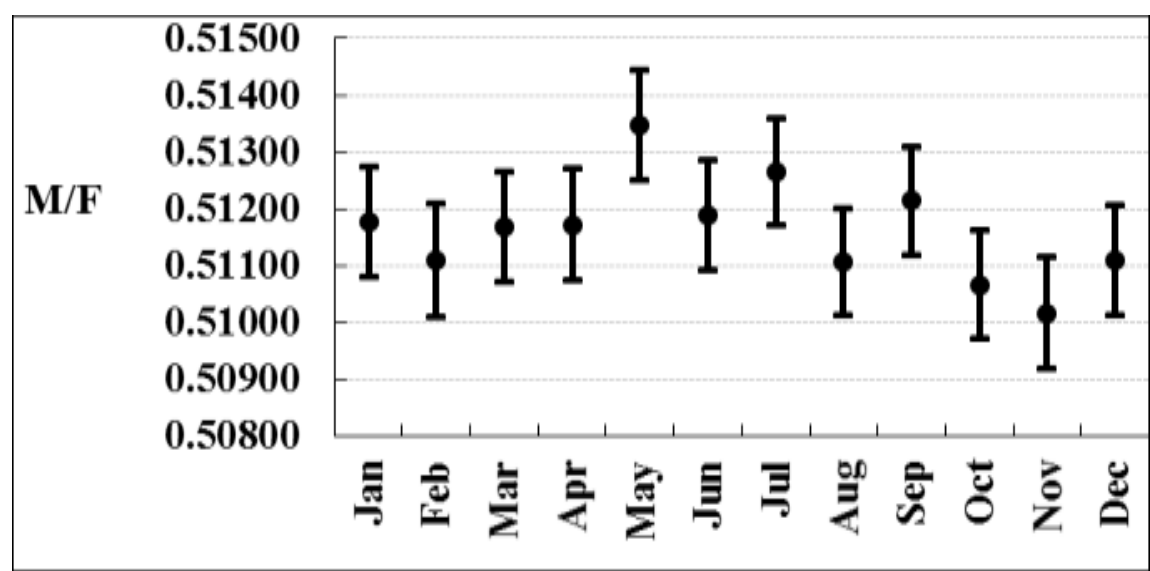

Fig 2: Monthly M/F for election years (2004, 2008 and 2012).

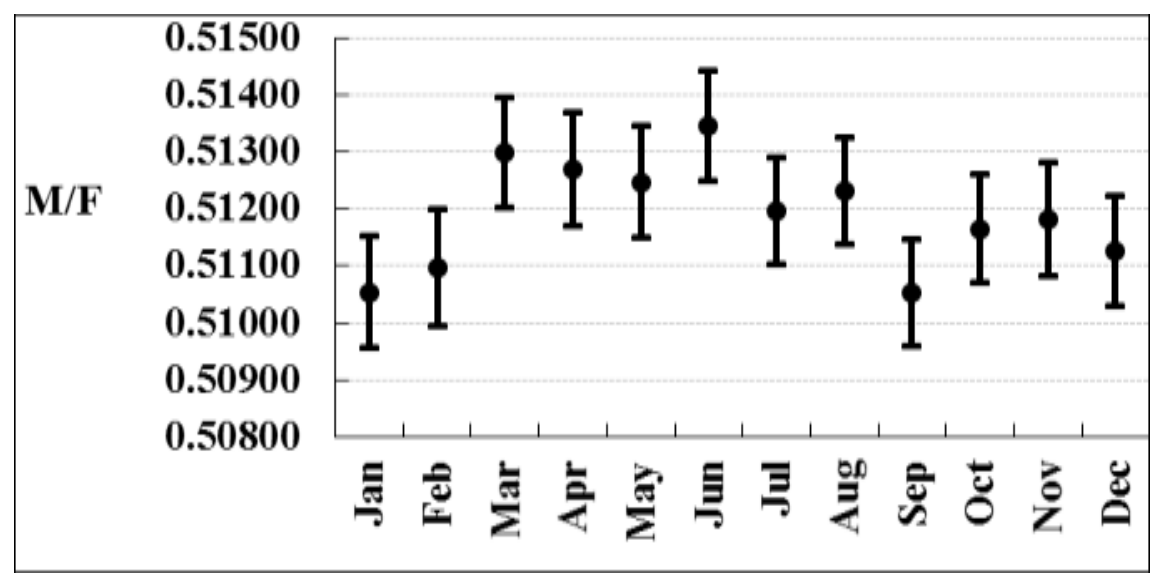

Fig 3: Monthly M/F for election years plus one (2005, 2009 and 2013). 


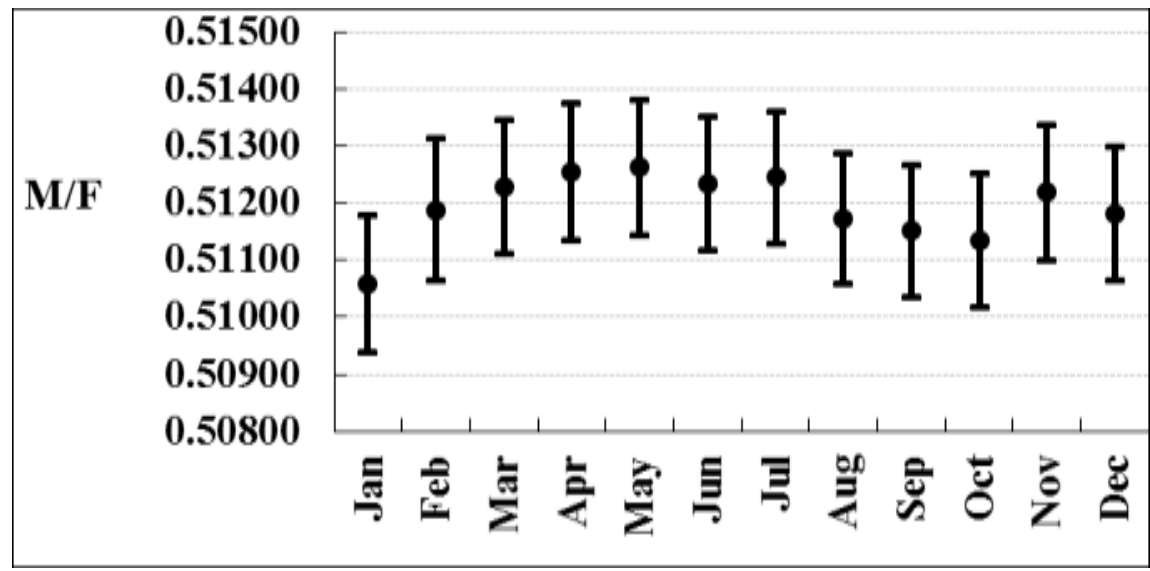

Fig 4: Monthly M/F for election years plus two $(2006,2010)$.

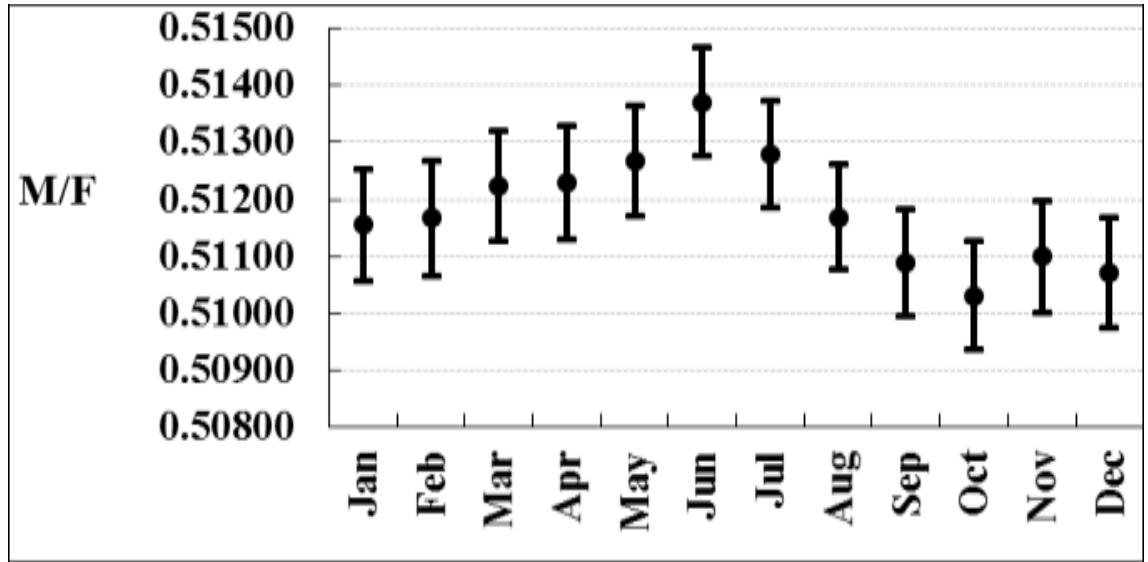

Fig 5: Monthly M/F for election years plus three (pre-election years: 2003, 2007, 2011). 